\title{
Сорбционные свойства угольно-минерального сорбента на основе рисовой лузги по отношению к ионам тяжелых металлов
}

\author{
(C) 2019 Меретин Р.Н. \\ Астраханский государственный университет, Астрахань \\ Поступила в редакцию 26.08.2019 г.
}

DOI: $10.17308 /$ sorpchrom.2019.19/2232

Получен новый угольно-минеральный сорбент из рисовой лузги. Исследованы его структура, поверхность и пористость. Изучена сорбция ионов токсичных металлов из водных растворов данным сорбентом. Определены величины их предельной сорбции $a_{\sim}$, константы сорбционного равновесия $\mathrm{k}$, термодинамические потенциалы сорбции (изменение энтальпии $\Delta \mathrm{H}^{\circ}$, энтропии $\Delta \mathrm{S}^{\circ}$, свободной энергии $\Delta \mathrm{G}^{\circ}$ ). Экспериментальные данные по сорбции обработаны в рамках модели Ленгмюра. На поверхности сорбента обнаружены карбоксильные -СООН группы, спиртовые и фенольные гидроксилы -ОН, силанольные группы -Si-OH, которые выступают в роли активных центров сорбции. Результаты проведённых исследований показали, что полученный сорбент эффективно извлекает ионы тяжёлых металлов из различных водных растворов. Материал данной статьи может представлять интерес для специалистов, работающих в области теории и практики адсорбционных явлений и процессов.

Ключевые слова: угольно-минеральный сорбент, ионы железа(II), меди(II), цинка, активные центры, сорбция.

\section{Sorption properties of coal-mineral sorbent based on rice husk in relation to heavy metal ions}

\author{
(C) 2019 Meretin R.N. \\ Astrakhan State University, Department of analytical and physical chemistry, Astrakhan
}

A new coal-mineral sorbent from rice husk was obtained. Its structure, surface and porosity were investigated. A significant amount of silicon dioxide was found in the resulting sorbent. Sorption of ions of toxic metals from aqueous solutions by this sorbent was studied. The values of the limit of the sorption $a_{\sim}$, constants the sorption equilibrium $\mathrm{k}$, the thermodynamic potentials of adsorption (change in enthalpy $\Delta \mathrm{H}^{\circ}$ and entropy $\Delta S^{\circ}$, and free energy $\Delta G^{\circ}$ ). Experimental data on sorption treated in the framework of the model of Langmuir. On the surface of the sorbent carboxyl groups $-\mathrm{COOH}$, alcoholic and phenolic hydroxyl $-\mathrm{OH}$, silanol -Si-OH groups were found, which act as active sorption centers. Si-O-Si bonds were detected in the sorbent; the presence of $\mathrm{Si}-\mathrm{OH}$ and $\mathrm{Si}-\mathrm{H}$ bonds was also revealed. The IR spectroscopy method showed the absence in the samples obtained after sorption of the formation of pronounced silicate bonds $\mathrm{Si}-\mathrm{O}-\mathrm{M}(\mathrm{M}=$ $\mathrm{Fe}, \mathrm{Cu}, \mathrm{Zn}$ ). At the same time, it was found that sorption of metal ions occurs at the anionic centers of the sorbent according to the ion exchange mechanism. The results of the studies showed that the resulting sorbent effectively extracts heavy metal ions from various aqueous solutions. In general, the sorbent obtained on the basis of rice husk can be very promising, since it is cheap and has a sufficiently high sorption capacity. The material of this article may be of interest to specialists working in the field of theory and practice of adsorption phenomena and processes.

Keywords: coal-mineral sorbent, ions of iron(II), copper(II), zinc, active centers, sorption 


\section{Введение}

Сорбция является универсальным методом, позволяющим практически полностью извлекать ионы тяжёлых металлов из водной среды. Для этих целей используются разнообразные сорбенты, к которым предъявляются определённые требования: хорошая поглотительная способность, избирательность, механическая устойчивость. При выборе сорбентов учитывают и экономические соображения, стараются применять относительно недорогие поглотители, особенно в тех случаях, когда они используются однократно. При этом традиционные виды сорбентов (активированные угли, цеолиты) нередко заменяются материалами из второсортного сырья, в частности, из отходов производства. Особое внимание привлекают разнообразные продукты растительного происхождения, характеризующиеся доступностью и низкой стоимостью [1].

Процесс получения таких материалов основан на сжигании (карбонизации) растительных компонентов, таких как косточки плодов фруктовых деревьев, скорлупа грецких орехов, пшеничные отруби и т.д. В литературе также имеются данные по производству сорбентов из лузги риса $[2,3]$. Согласно литературным данным, рисовая лузга широко используется при производстве активированного угля, благодаря тому, что она представляет собой лигноцеллюлозную биомассу, которая состоит из лигнина, целлюлозы и гемицеллюлозы [4]. Лигнин является основным компонентом, из которого образуется уголь, отвечающий за процесс адсорбции, а целлюлоза и гемицеллюлоза являются летучими фракциями, удаляемыми во время пиролиза, что способствует образованию микропор [5]. Рисовая лузга отличается высоким содержанием золы, в которой 76-99\% от общей массы приходится на диоксид кремния $\left(\mathrm{SiO}_{2}\right)$, а также обнаруживается незначительное количество металлических примесей [6]. В данной работе на примере сорбции ионов железа(II), меди(II) и цинка(II) изучены свойства нового сорбента, представляющего собой продукт термохимической обработки рисовой лузги.

\section{Эксперимент}

Для получения сорбента рисовую лузгу, которая была предварительно промыта водой и высушена при $105^{\circ} \mathrm{C}$, нагревали при $450-500^{\circ} \mathrm{C}$ в течение 8-10 минут до потери $\sim 60 \%$ массы. Образовавшийся остаток остужали в дистиллированной воде (1:5), фильтровали, обрабатывали 2\%-ным раствором уксусной кислоты с целью извлечения из сорбента поверхностных минеральных примесей, кислый раствор сливали, осадок тщательно промывали бидистиллированной водой и высушивали при $100-150^{\circ} \mathrm{C}$ до постоянной массы. Высушенный материал измельчали дроблением в фарфоровой посуде. Растворы, содержащие ионы металлов с концентрацией $0.01 \mathrm{M}$, готовили на дистиллированной воде из точной навески солей металлов. Использовали следующие соли: $\mathrm{ZnSO}_{4} \cdot 7 \mathrm{H}_{2} \mathrm{O}, \mathrm{CuSO}_{4} \cdot 5 \mathrm{H}_{2} \mathrm{O}, \mathrm{FeSO}_{4} \cdot 7 \mathrm{H}_{2} \mathrm{O}$. Рабочие растворы готовили разбавлением исходных. В качестве органического реагента для определения ионов металлов применяли пиридилазорезорцин (ПАР) квалификации ч.д.а. Реагенты имели квалификацию ч., х.ч. или ч.д.а.

Идентификацию фазового состава сорбента осуществляли посредством рентгеновского дифракционного анализа на автоматическом порошковом дифрактометре D2Phaser (Bruker) с использованием базы порошковых дифракционных данных PowderDiffractionFile (PDF-2, 2011) в программе PDXL2.0/.

Для оценки сорбционной способности полученного образца были проведены исследования на приборе Quantachrome ASIQwin, который по низкотемпературной 
адсорбции азота позволил определить его удельную поверхность, средний диаметр и общий объём пор.

Время установления равновесия в гетерофазной системе «водный растворсорбент» определяли следующим образом. Готовили по $500 \mathrm{~cm}^{3}$ растворов соли цинка с концентрацией $3 \cdot 10^{-5}$ моль/дм ${ }^{3}$, соли железа с концентрацией $3 \cdot 10^{-5}$ моль/дм ${ }^{3}$, соли меди с концентрацией $2.8 \cdot 10^{-5}$ моль/дм³. Отбирали по $10 \mathrm{~cm}^{3}$ из каждого раствора. Оставшийся раствор термостатировали в течение одного часа при $298 \pm 0.5 \mathrm{~K}$, $313 \pm 0.5$ К или погружали колбу в лёд, добиваясь того, чтобы температура системы находилась на уровне $278 \pm 0.5$ К. Вносили 5 г сорбента, одновременно включали секундомер, перемешивали и отбирали аликвоту объёмом $10 \mathrm{~cm}^{3}$ для измерения оптической плотности. Пробы отбирались через каждый час после начала сорбции. В пробирки с пробами вносили по 1 см $^{3}$ металлоиндикатора 4-(2-пиридилазо)резорцина (ПАР), полученные растворы перемешивали и проводили фотометрические измерения на спектрофотометре ПЭ-5300В относительно растворителя (вода дистиллированная) при длине оптического пути 1 см. Длина волны для определения ионов металлов соответствовала 495 нм. Время, при котором аналитический сигнал, регистрируемый в ходе анализа пробы, переставал существенно изменяться, считали временем, необходимым для установления равновесия.

Для изучения статической сорбции готовили растворы солей определяемых ионов металлов с известными концентрациями. В первую серию пробирок приливали $0.1 ; 0.3 ; 0.6 ; 0.8 ; 1.7 ; 2.5 ; 3.0 \mathrm{~cm}^{3} 10^{-4} \mathrm{M}$ раствора $\mathrm{FeSO}_{4}$, во вторую вносили 0.1 ; $0.5 ; 0.7 ; 1.2 ; 1.3 ; 2.5 ; 2.8 \mathrm{~cm}^{3} \mathrm{CuSO}_{4}$ с концентрацией $10^{-4}$ моль/дм ${ }^{3}$, в третью серию приливали $0.1 ; 0.3 ; 0.5 ; 1.0 ; 1.5 ; 1.8 ; 2.5 ; 2.7 ; 3.0 \mathrm{~cm}^{3} 10^{-4} \mathrm{M}$ раствора $\mathrm{ZnSO}_{4}$. Объёмы в пробирках доводили до $10 \mathrm{~cm}^{3}$ дистиллированной водой, приливали $1 \mathrm{~cm}^{3} 10^{-4} \mathrm{M}$ металлоиндикатора 4-(2-пиридилазо)резорцина (ПАР). Измеряли оптические плотности растворов при вышеописанных условиях. Исходя из полученных данных, строили градуировочные графики в координатах «оптическая плотность $A$ - концентрация ионов металла $C$ (моль/дм³)».

В центрифужные градуированные пробирки приливали растворы солей, как это описано для градуировочных графиков. Далее вносили по 0.1 г сорбента в каждую пробирку, перемешивали, проводили сорбцию при температурах $278 \pm 0.5$, $298 \pm 0.5$ и $313 \pm 0.5$ К. Содержимое пробирок центрифугировали, отделяли надосадочную жидкость, к которой приливали $1 \mathrm{~cm}^{3} 10^{-4} \mathrm{M}$ металлоиндикатора 4-(2пиридилазо)резорцина (ПАР) и измеряли оптические плотности полученных растворов. По градуировочным графикам с использованием результатов опытов определяли равновесные концентрации сорбируемых ионов. Избыточную сорбцию $(\Gamma$, моль/г) оценивали через величины исходной $\left(C_{0}\right)$, равновесной $[C]$ концентраций ионов металлов и массы сорбента $m$.

$$
\Gamma=\frac{C_{c o p \tilde{}}}{m}=\frac{\left(C_{0}-[C]\right) \cdot V}{m},
$$

где $C_{\text {сорб }}$ - концентрация сорбированного вещества (моль/дм³); $V$ - объём раствора $\left(\right.$ дм$\left.^{3}\right), m$ - масса сорбента, г.

Используя уравнение связи между абсолютной и избыточной сорбцией, рассчитали значения полных величин:

$$
a=\Gamma+\bar{C} .
$$

Здесь $a$ и $Г$ - значения абсолютной и избыточной сорбции; $\bar{C}-$ концентрация подвижных ионов в сорбенте, определяемая по формуле:

$$
\bar{C}=\frac{\omega \cdot C}{m},
$$


где $\omega$ - объём раствора в набухшем адсорбенте, дм³.

С целью выявления участия различных функциональных группировок сорбента в связывании ионов железа и меди были сняты ИК-спектры поглощения образцов до и после сорбции. Для этого 3 г сорбента помещали в колбу коническую и приливали $20 \mathrm{~cm}^{3}$ раствора соли, содержащей $10 \mathrm{мг} /$ дм³ $^{3}$ иона металла. По окончании сорбции раствор фильтровали, сорбент отделяли, высушивали в естественных условиях. Образцы были спрессованы в таблетки с KBr. Инфракрасные спектры получены на ИК-Фурье спектрометре Nicolet 8700 (ThermoFisherScientific) в режиме пропускания, используя детектор МСТ, охлаждаемый азотом. Интерпретация полученных ИК-спектров проводилась с использованием сведений, представленных в работе [7]. Обработка экспериментальных данных осуществлялась в соответствии с формулами и алгоритмами, описанными в справочнике [8].

\section{Обсуждение результатов}

Сорбент представляет собой тонкодисперсный порошок чёрного цвета с диаметром частиц менее 0.1 мм. Полученный образец был воздушно-сухим с влажностью $1.7 \%$. Результаты исследования сорбента методом рентгенодифракционного фазового анализа показывают, что данный образец содержит аморфную фазу (не менее $80 \%$ ), которая представлена аморфным углеродом и аморфным $\mathrm{SiO}_{2}$. Также в его составе имеется кристаллическая фаза, представленная графитом. Потери при прокаливании образца позволили оценить содержание диоксида кремния в сорбенте, составляющего $35 \%$ от общей массы.

Установлено, что удельная поверхность сорбента достигает $309.19 \mathrm{~m}^{2} /$, средний диаметр и общий объём пор составляют 3.73 нм и $1.405 \cdot 10^{-2} \mathrm{~cm}^{3}$ соответственно. Исследуемый материал обладает более развитой поверхностью и пористостью в сравнении с рядом других известных растительных сорбентов [9].

На рис. 1 показаны изотермы сорбции железа и цинка из водных растворов при различных температурах. Данный вид изотерм характеризует случай мономолекулярной сорбции на однородной поверхности [10].

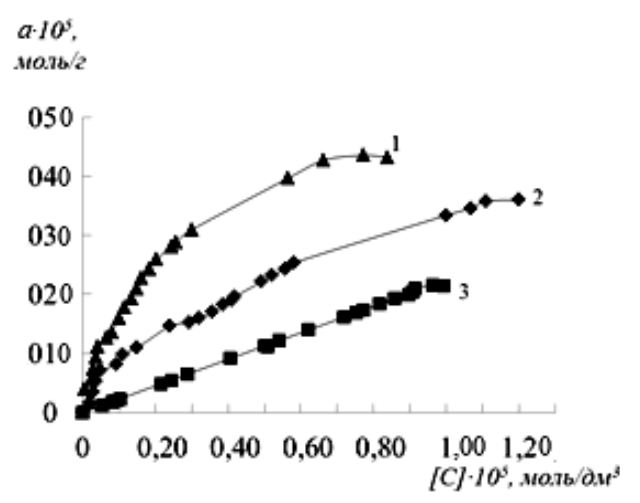

$a$

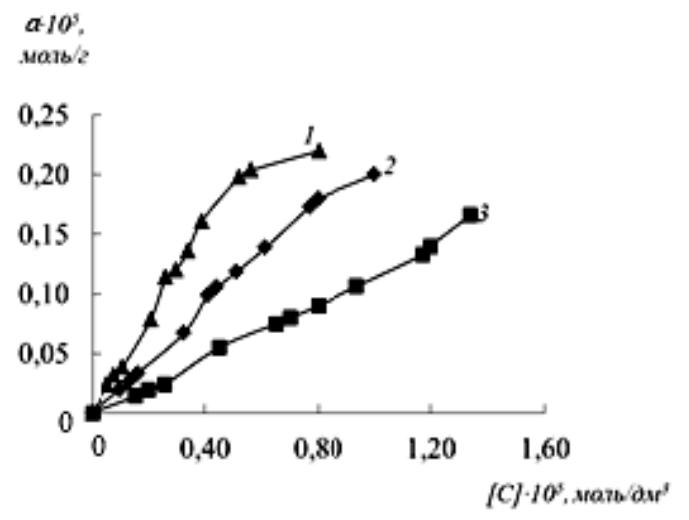

6

Рис. 1. Изотермы сорбции ионов металлов: $a-$ железо, $\sigma$ - цинк при температурах: $1-278$ К, 2 - 298 К, 3 - 313 К

Аппроксимация изотерм по уравнению Ленгмюра позволила определить величину их максимальной сорбции $a_{\sim}$. При температуре 298 К она составила $17.40 \pm 0.14$ мг/Г для железа, $15.27 \pm 0.04$ мг/г для цинка, $14.80 \pm 0.35$ мг/г для меди.

Определение константы сорбционного равновесия $k$ дано в работе [11]: 


$$
k=\lim _{c_{a} \rightarrow 0} \frac{C_{a}}{C_{p}},
$$

где $C_{a}$ - концентрация растворённого вещества в сорбционной фазе, $C_{p}-$ концентрация этого же вещества в объёмной фазе.

Одним из основных параметров сорбируемости из раствора является стандартное изменение энергии Гиббса, определяемое из константы равновесия

$$
\Delta G^{o}=-R T \ln k
$$

Энтальпия $\left(\Delta H^{0}\right)$ определялась по изостерам сорбции как зависимость логарифма равновесной концентрации от обратной величины температуры.

Значения $\Delta H^{\circ}$ и $\Delta G^{\circ}$ позволили рассчитать изменения энтропии сорбционного процесса $\Delta S^{\circ}$ :

$$
\Delta G^{o}=\Lambda H^{o}-T \Delta S^{o}
$$

Отрицательные значения $\Delta H^{\circ}$ и отрицательные величины $\Delta G^{o}$ (табл.), увеличивающиеся с ростом температуры в интервале $278-313$ К, говорят о том, что процесс сорбции ионов тяжелых металлов на исследуемом сорбенте носит экзотермический характер. Рассчитанные изменения энтропий адсорбции $\Delta S^{\circ}$ положительны, что позволяет говорить об уменьшении упорядоченности системы. Сорбция ионов металлов более предпочтительна при пониженных температурах.

Таблица. Константы и основные термодинамические характеристики сорбции ионов металлов

\begin{tabular}{|c|c|c|c|c|}
\hline \multicolumn{2}{|c|}{ Ион металла } & $\mathrm{Cu}^{2+}$ & $\mathrm{Fe}^{2+}$ & $\mathrm{Zn}^{2+}$ \\
\hline \multirow{2}{*}{$\begin{array}{c}\text { Константа сорбции } \mathrm{k} \cdot 10^{-2} \\
\text { при различных } \\
\text { температурах, } \mathrm{K}\end{array}$} & 313 & $15.95 \pm 0.85$ & $13.34 \pm 0.58$ & $9.52 \pm 0.32$ \\
\cline { 2 - 5 } & 298 & $18.63 \pm 0.64$ & $24.32 \pm 0.71$ & $15.26 \pm 0.32$ \\
\hline \multicolumn{2}{|c|}{$\Delta \mathrm{G}^{0}$, кДж/моль при $298 \mathrm{~K}$} & $23.49 \pm 0.44$ & $38.46 \pm 0.60$ & $20.02 \pm 0.62$ \\
\hline \multicolumn{2}{|c|}{$-\Delta \mathrm{H}^{0}$, кДж/моль } & $18.65 \pm 0.86$ & $19.31 \pm 0.71$ & $18.16 \pm 0.05$ \\
\hline \multicolumn{2}{|c|}{$\Delta \mathrm{S}^{0}$, Дж/моль $\mathrm{K}$} & $156.79 \pm 3.35$ & $134.10 \pm 11.22$ & $115.32 \pm 0.36$ \\
\hline
\end{tabular}

Образцы полученной в работе карбонизированной рисовой лузги до и после сорбции ионов $\mathrm{Cu}^{2+}$ и $\mathrm{Fe}^{2+}$ были исследованы методом ИК-спектроскопии для того, чтобы определить, какие функциональные группы принимают участие в сорбции.

На рис. 2 представлены ИК-спектры образцов сорбента, снятых до и после сорбции ионов $\mathrm{Cu}^{2+}$ и $\mathrm{Fe}^{2+}$.

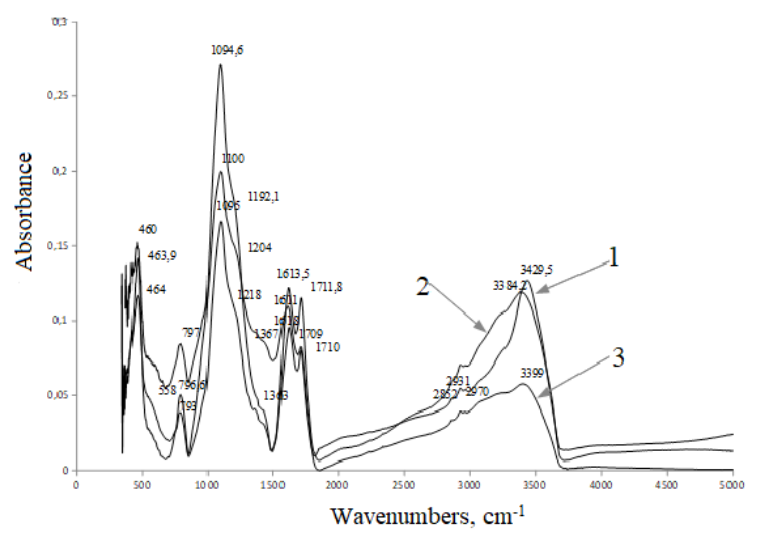

Рис.2. ИК-спектры образцов сорбента, полученного из рисовой лузги: 1 - до сорбции; 2,3 - после сорбции ионов $\mathrm{Fe}^{2+}, \mathrm{Cu}^{2+}$ 
Следует отметить, что ИК-спектры имеют сложный характер. Широкие полосы в области 3380-3430 $\mathrm{cm}^{-1}$ обусловлены деформационными и валентными колебаниями ОН-групп молекул воды. В области спектра 3300-3400 см-1 проявляются деформационные колебания связи О-Н, в том числе, в составе фенольных групп на поверхности угля [12].

Полосы при 2923, 1709 и $1618 \mathrm{~cm}^{-1}$ в спектре сорбента до сорбции соответствуют деформационным колебаниям связей $\mathrm{C}-\mathrm{H}, \mathrm{C}=\mathrm{O}$ и $\mathrm{O}-\mathrm{H}$, соответственно [13]. Эти пики, вероятно, обусловлены наличием функциональных групп частично разложившихся органических соединений: целлюлозы, гемицеллюлозы и лигнина в карбонизированном образце.

Кроме того, в спектрах всех образцов наблюдались полосы поглощения в области 460-464, 793-797 и 1095-1100 см-1 , отвечающие деформационным и валентным (симметричным и асимметричным) колебаниям силоксановых связей $\mathrm{Si}-\mathrm{O}-\mathrm{Si}$ [14]. Эти полосы поглощения имеют большую интенсивность и свидетельствуют о высоком содержании диоксида кремния в сорбенте. Важной функциональной группой в кремнийсодержащих веществах, от которой зависит химическое поведение поверхности, является силанольная группа ( $\mathrm{Si}-\mathrm{OH})$. О присутствии силанольных связей свидетельствует появление полосы 830-910 см${ }^{-1}$ в ИК-спектрах кремнийсодержащих соединений [15]. В исследуемых образцах в этой области спектров имеется лишь небольшой (мало заметный) излом, что не позволяет уверенно связывать сорбцию ионов тяжёлых металлов с участием в этом процессе силанольных связей $\mathrm{Si}-\mathrm{OH}$.

При сравнении ИК-спектров исследуемых образцов сорбента наблюдается изменение положения полос в спектрах образцов после сорбции ионов $\mathrm{Fe}^{2+}$ и $\mathrm{Cu}^{2+}$ относительно положения полос в спектре образца до сорбции. Наибольшие сдвиги отмечаются в областях ИК-спектра, отвечающих колебаниям связей О-H, C-H и $\mathrm{C}=\mathrm{O}$.

Так, полоса при $3429 \mathrm{~cm}^{-1}$ в спектре сорбента до сорбции ионов тяжёлых металлов смещается в положения 3384 и $3399 \mathrm{~cm}^{-1}$ после сорбции ионов железа и меди, где проявляются деформационные колебания связи О-Н, в том числе, в составе фенольных групп. Пики, отвечающие колебаниям связи $\mathrm{C}=\mathrm{O}$ при $1709 \mathrm{~cm}^{-1}$ в спектре исходного образца, смещаются в положения 1710 и $1712 \mathrm{~cm}^{-1}$ в спектрах образцов, полученных после сорбции ионов $\mathrm{Fe}^{2+}$ и $\mathrm{Cu}^{2+}$. Полоса при $1095 \mathrm{~cm}^{-1}$ в спектре сорбента, не содержащего металлов, обнаруживается в спектрах образцов, полученных после сорбции ионов меди и железа при 1100 и $1094 \mathrm{~cm}^{-1}$, соответственно. Таким образом, можно заключить, что именно эти функциональные группы, присутствующие в сорбенте, полученном на основе рисовой лузги, отвечают за сорбцию ионов тяжёлых металлов из водных растворов. Сделанный вывод согласуется с литературными данными.

\section{Заключение}

Сорбент, получаемый на основе рисовой лузги, относится к серии углерод- и кремнийсодержащих продуктов, характеристика и, следовательно, свойства которых зависят от сырья и условий получения. В нём присутствуют функциональные группы, оставшиеся от исходной лузги, а также принадлежащие углю и кремнезему. Данный сорбент дешев, обладает достаточно высокой сорбционной емкостью и может быть эффективно использован с целью снижения содержания ионов тяжёлых металлов в различных водных и смешанных водно-органических системах. 


\section{Список литературы}

1. Никифорова Т.Е., Козлов В.А., Родионова М.В., Модина Е.А. // Изв.вузов. Химия и хим. технология. 2009. Т. 52. № 3. С. 27-31.

2. Холомейдик А.Н., Земнухова Л.А. // Эк. и пром. России. 2011. № 11. С. 34-35.

3. Шевелева И.В., Холомейдик А.Н., Войт А.В., Земнухова Л.А. // Химия растительного сырья. 2009. № 4. С. 171-176.

4. Menyaa E., Olupot P.W., Storz H., Lubwama M., Kiros Y. // Engineering Research and Design. 2018. Vol.129. pp. 271-296.

5. Correa Rodriguez C., Otto T., Kruse A. // Biomass Bioenergy. 2017. Vol. 97. pp. 53-64.

6. Palagama D.S.W., Devasurendra A.M., Baliu-Rodriguez D., Kirchhoff J.R. et al. // Science of the Total Environment. 2019. Vol. 666. pp.1292-1300.

7. Сильверстейн Р., Вебстер Ф., Кимл Д. Спектрометрическая идентификация органических соединений. М. Бином. Лаборатория знаний. $2011.557 \mathrm{c}$.

8. Королюк В.С., Портенко Н.И., Скороход А.В., Турбин А.Ф. Справочник по теории вероятностей и математической статистике. М. Наука. 1987. 640 с.

\section{References}

1. Nikiforova T.E., Kozlov V.A., Rodionova M.V., Modina E.A., News of universities. Chemistry and chemical technology, 2009, Vol. 52, No 3, pp. 27-31.

2. Holomejdik A.N., Zemnuhova L.A., Ecol. and indust. of Russia, 2011, No 11, pp. 34-35.

3. Sheveleva I.V., Holomejdik A.N., Vojt A.V., Zemnuhova L.A., Chemistry of plant raw materials, 2009, No 4, pp. 171-176.

4. Menyaa E., Olupot P.W., Storz H., Lubwama M., Kiros Y., Engineering Research and Design, 2018, Vol.129, pp. 271-296.

5. Correa Rodriguez C., Otto T., Kruse A., Biomass Bioenergy, 2017, Vol. 97, pp. 53-64.

6. Palagama D.S.W., Devasurendra A.M., Baliu-Rodriguez D., Kirchhoff J.R., Isailovic D., Science of the Total Environment, 2019, Vol. 666, pp. 1292-1300.

7. Sil'verstejn R., Vebster F., Kiml D. Spektrometricheskaja identifikacija organicheskih soedinenij. Moscow, Binom, Laboratorija
9. Никифорова Т.Е., Козлов В.А., Натареев С.В., Соловьёва Е.А. и др. // Изв.вузов. Химия и хим. технология. 2012. Т. 55. № 7. С. 22-27.

10. Толмачёв А.М. Адсорбция газов, паров и растворов. М. «Издательская группа «Граница». 2012. 241 с.

11. Авраменко В.А., Глущенко В.Ю., Шестёркин В.П. // Журнал физической химии. 1977. Т. 51. № 9. C. 2304-2306.

12. Koiodyniska D., Krukowska J., Thomas P. // Chemical Engineering Journal. 2017. Vol. 307. pp. 353-363.

13. Rafiee E., Shahebrahimi S., Feyzi M., Shaterzadeh M. // International Nano Letters. 2012. Vol. 2. No 1. p. 29.

14. Lee T., Othman R., Yeoh F.-Y. // Biomass Bioenergy. 2013. Vol. 59. pp. 380-392.

15. Зулумян Н.О., Исаакян А.Р., Пирумян П.А., Бегларян А.А. // Журнал физической химии. 2010. Т. 84. № 4. С. 791-793.

znanij, 2011, $557 \mathrm{p}$.

8. Koroljuk V.S., Portenko N.I., Skorohod A.V., Turbin A.F. Spravochnik po teorii verojatnostej i matematicheskoj statistike. M., Nauka Publ., 1985, 640 p.

9. Nikiforova T.E., Kozlov V.A., Natareev S.V., Solov'jova E.A. et al., News of universities. Chemistry and chemical technology, 2012, Vol. 55, No 7, pp. 22-27.

10. Tolmachjov A.M. Adsorbcija gazov, parov i rastvorov, M., Izdatel'skaya gruppa "Granica", 2012, $241 \mathrm{p}$.

11.Avramenko V.A., Glushhenko V.Yu., Shestjorkin V.P., Journal of physical chemistry, 1977, Vol. 51, No 9, pp. 2304-2306.

12.Kołodyn'ska D., Krukowska J., Thomas P., Chemical Engineering Journal, 2017, Vol. 307, pp. 353-363.

13.Rafiee E., Shahebrahimi S., Feyzi M., Shaterzadeh M., Int. Nano Lett., 2012, Vol. 2, No 1, p. 29. 
14.Lee T., Othman R., Yeoh F.-Y., Biomass Bioenergy, 2013, Vol. 59, pp. 380-392.

15.Zulumjan N.O., Isaakjan A.R., Pirumjan

Меретин Роман Николаевич - аспирант кафедры аналитической и физической химии, Астраханский государственный университет, Астрахань
P.A., Beglarjan A.A., Journal of physical chemistry, 2010, Vol. 84, No 4, pp. 791-793.

Meretin Roman N. - post graduate, department of analytical and physical chemistry, Astrakhan state university, Astrakhan, e-mail: roman_meretin@mail.ru 